Bulletin UASVM Food Science and Technology 70(2)/2013, 129-136

ISSN-L 2344-2344; Print ISSN 2344-2344; Electronic ISSN 2344-5300

\title{
Convective Air Drying Characteristics for Thin Layer Carrots
}

\section{Ionuţ Dumitru VELEȘCU, Ioan ŢENU, Petru CÂRLESCU, Vasile DOBRE}

\author{
University of Applied Life Science and Environment, Iași, România; Iasi, Aleea Mihail Sadoveanu nr. 3 \\ i.velescu@yahoo.com
}

\begin{abstract}
This paper presents a kinetic study of convective drying without pre-treatment of carrot. The effects of the temperature of the drying agent, the speed of the drying agent and the thickness of the kinetics of drying the sample of carrots were investigated. The experiments were carried out with the aid of an installation for drying food products, that is capable of ensuring the temperature of the drying agent (air) in the range of $+25 \ldots+125{ }^{\circ} \mathrm{C}$. The drying process was conducted at temperature of $45{ }^{\circ} \mathrm{C}$ in first hour of process, 2 hours at $55^{\circ} \mathrm{C}$, and 3 hours at $60{ }^{\circ} \mathrm{C}$. The air velocity was setup at $1.0-2.5 \mathrm{~m} / \mathrm{s}$. Carrots were divided into segments of a thickness of $0.4 \mathrm{~cm}$. Two mathematical models available in the literature were fitted to the experimental data. The drying rate increases with temperature and decreases with the sample diameter. The Page model is given better prediction than the Henderson and Pabis model and satisfactorily described drying characteristics of carrot slices. In conclusion, the effective diffusivity increases as air-flow rate and temperature increases. Page's empirical model showed a good fit curves than the Henderson and Pabis model.
\end{abstract}

Keywords: dryer, carrot, mathematical modelling, drying process

\section{INTRODUCTION}

Carrot is one of the most commonly used vegetables for human nutrition due to high vitamin and fibre content. Carrot is an excellent source of beta carotenes reported to prevent cancer, vitamin $\mathrm{A}$, and potassium, and it contains cholesterol-lowering pectin, vitamin $\mathrm{C}$, vitamin B6, thiamine, folic acid, and magnesium.

Drying is one of the oldest methods of food preservation, and it represents a very important aspect of food processing. Sun drying is the most common method used to preserve agricultural products in most tropical countries; this technique is extremely weather dependent, and has the problems of contamination with dust, soil, sand particles and insects (Brennan, 2006; Mujumdar, 2006).

Also, the required drying time can be quite long. Therefore, using solar and hot-air dryers, which are far more rapid, providing uniformity and hygiene are inevitable for industrial food drying processes. The main objective of drying agricultural products is the reduction of the moisture content to a level which allows safe storage over an extended the period. It also brings about substantial reduction in weight and volume, minimises packaging, storage and transportation costs (Catană Luminița et al., 2008).

Conventional air-drying is the most frequently used dehydration operation in food industry. Dried carrots are used in dehydrated soups and in the form of powder in pastries and sauces. A number of researchers have studied the dehydration behavior of carrot slices, cubes, osmosed carrot cubes, shreds and carrot pomace. Doymaz (2007) studied the convective drying characteristics of carrot cubes and revealed that effective moisture diffusivity increased with increase in temperature. 
The drying process is a complex process that runs in two stages. In the first hour evaporation is carried with high speed, eliminating free water, and then drying speed is reduced gradually in proportion to the product moisture reduction (Doymaz I., 2002).

The aims of this paper is study the kinetic of convective drying without pre-treatment of carrot, the effect of process parameters such as drying temperature, air-flow rate and simple thickness and to estimate the constants of selected model equations as well as diffusion coefficient and activation energy, for drying of carrot.

\section{MATERIALS AND METHODS}

Fresh carrots were procured from the local market of supermarket of Iasi. The carrots were washed, trimmed and manually peeled and again washed to remove adhered peels on the surface.

At the start of each experiment, the carrots were washed and cut into slices, having the dimensions of $0.4 \mathrm{~cm}$ using a kitchen slicer. Carrots slices were not treated in any way before drying. The carrots slices were spread in a tray in a single layer.

The drying of carrot slices was investigated in vertical laboratory dryer (Fig. 1a) belonging to Agricultural Mechanization Department of the University of Agricultural Sciences and Veterinary Medicine (T,enu et. al., 2012). The dryer basically consist of a centrifugal fan to supply the airflow, an electric heater and an electronic proportional controller (Fig. 1b). The hot air dryer is capable of providing the desired drying air temperature in the range of $25{ }^{\circ} \mathrm{C}$ to 125 ${ }^{\circ} \mathrm{C}$ and air relative humidity in the range of $10 \%$ to $100 \%$; in dryer the hot air pass perpendicularly (from the bottom up) through a thin layer of onion slices. The dryer is equipped with its own thermostat that controls the heating temperature and maintain constant.

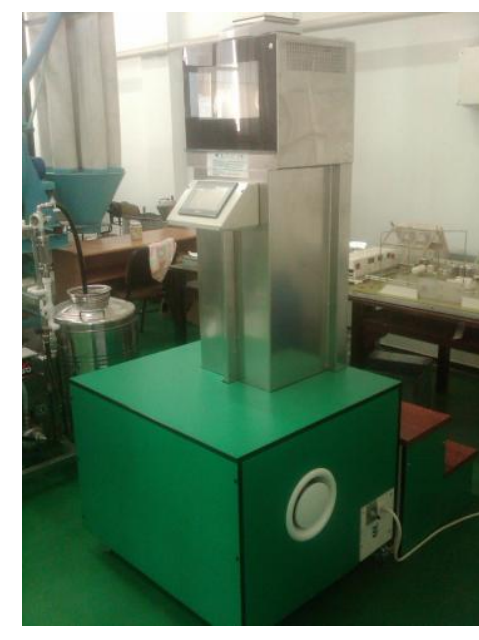

a

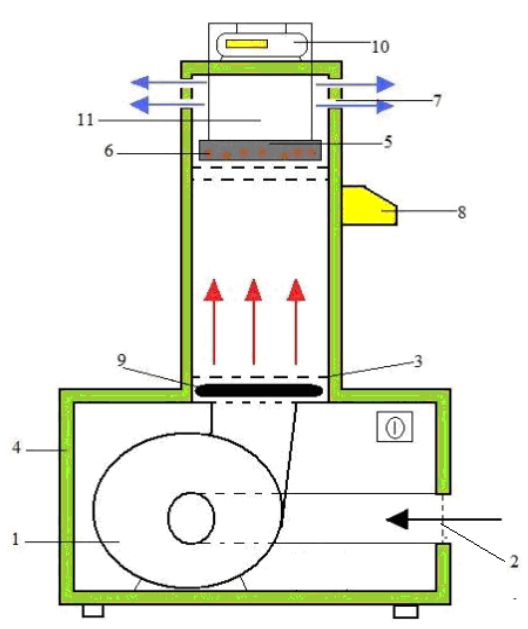

b

Fig. 1. Installation for drying: a - general view; $b$ - scheme of the installation:

1 - fan; 2 - the air inlet pipe, 3 - grill, 4 - thermal insulation, 5 - tray product, 6 - products subjected to drying, 7 - exhaust of the drying agent, 8 - Interface touch - screen;

9 - electric heaters of air, 10 - electronic balance; 11 - drying room, 12 - electric motor

The dryer operates in discontinuous after a cycle according the nature of product, to the following stages: feeding fresh product tray, placement in a uniform layer, and entry into the 
drying chamber, drying the product by sealing the dryer enclosure, switch on the fan and electrical items, cooling fruit dehydrated product.

During the drying experiments, air-flow rates of 1.0, 1.5, 2.0 and $2.5 \mathrm{~m} / \mathrm{s}$ of drying agent is controlled by fan speed and is measured with Testo 410 Anemometer (Fig. 2a). During the experiments the temperature of carrot sample were measured with Testo 925 Thermometer, T/C type K (Fig. 2b).

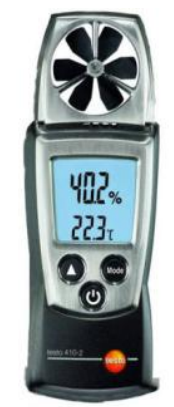

a

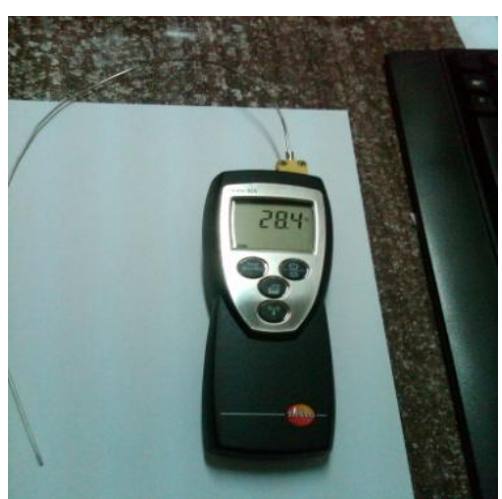

b

Fig. 2. Devices for measuring the temperature and velocity the drying agent a - Testo 410 Anemometer; b- Testo 925 Thermometer

The samples were dried in the perforated square chamber of $30 \mathrm{~cm}$ x $30 \mathrm{~cm}$. The moisture content of the carrot during the drying process was determined by difference in weight of the sample resulting from the weighing. Reducing the moisture content was recorded by measuring the weight of the carrot throughout the drying process (every hour).

The drying process was conducted at temperature of $45{ }^{\circ} \mathrm{C}$ in first hour of process, 2 hours at $55{ }^{\circ} \mathrm{C}$, and 3 hours at $60{ }^{\circ} \mathrm{C}$. Determination of initial and final water content of carrot is also achieved by heat balance method (Fig. 3).

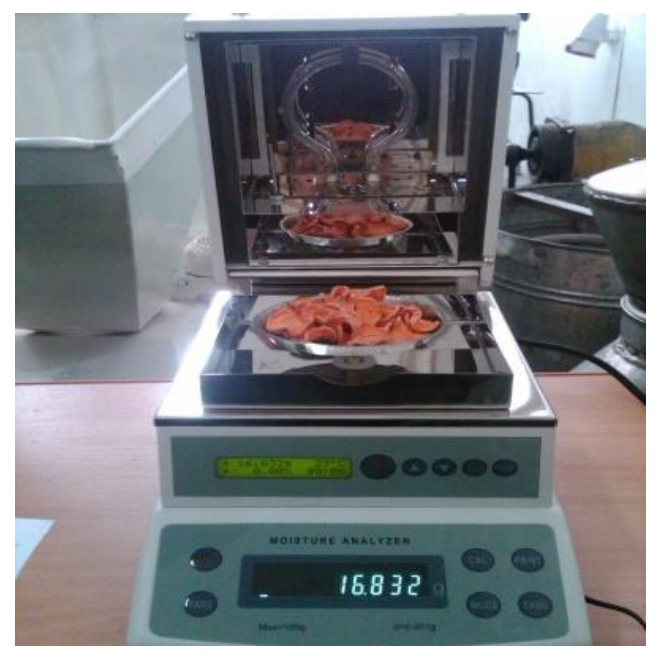

Fig. 3. Heat balance

The moisture content was expressed as a percentage wet basis, and then converted to gram water per gram dry matter. The moisture ratio (MR) of the carrot slices was determined using: 


$$
M R=\frac{M_{x}-M_{e}}{M_{0}-M_{e}}
$$

Where MR is the moisture ratio, $M_{x}$ - product moisture at time $t, M_{e}$ - moisture equilibrium; $M_{0}$ - initial moisture content of the product.

Drying curve. The moisture content of the samples was found during the drying process using:

$$
M_{x}=\frac{W_{x}-W_{d}}{W_{d}}
$$

The product was cooled for $20 \mathrm{~min}$ after drying. The rehydration ratio of dried carrot slices was determined by immersing samples in water at $20^{\circ} \mathrm{C}$ for 30,60 and 120 minutes. Rehydration Capacity $(\mathrm{RC})$ in described as:

$$
R C=\frac{\text { Weight of water absorbed during rehydration }}{\text { Weight of water removed during drying }} \times 100
$$

The calculated moisture ratio (MR) was fitted to two commonly used thin-layer drying models shown in Tab. 1 by using non-linear least squares regression. Three criteria were used to select the best model for describing the drying kinetics of carrot, coefficient of determination $\left(R^{2}\right)$ and standard error (SE).

Tab. 1

Mathematical models applied to the drying curves

\begin{tabular}{|l|c|c|}
\hline \multicolumn{1}{|c|}{ Model } & Equation & Reference \\
\hline Page & MR $=\exp \left(-\mathbf{k} \mathbf{t}^{\mathbf{n}}\right)$ & M. J. Vázquez-Vila et. al.(2009) \\
\hline Henderson and Pabis & MR $=\boldsymbol{a} \exp (-\mathbf{k t})$ & Ibrahim Doymaz (2004) \\
\hline
\end{tabular}

\section{RESULTS AND DISCUSSIONS}

Experiments were carried out after drying the following chart:

- $\quad$ During the first hour of drying, the temperature of the drying was $45^{\circ} \mathrm{C}$;

- $\quad$ The following three (3) hours of drying, the temperature was kept constant at $55^{\circ} \mathrm{C}$;

- $\quad$ In the last 2 (two) hours of the drying process, the temperature was raised to $60{ }^{\circ} \mathrm{C}$.

On the other hand, the speed of the drying agent (ambient air) had different values as follows:

- $\boldsymbol{M 1}$ - the speed of the drying agent was $2.5 \mathrm{~m} / \mathrm{s}$;

- M2 - speed of agent was $2.0 \mathrm{~m} / \mathrm{s}$;

- M3 - speed drying agent was $1.5 \mathrm{~m} / \mathrm{s}$;

- M4 - speed was $1.0 \mathrm{~m} / \mathrm{s}$.

During all experiments (four repetitions for each speed the drying agent) agent humidity was $20-25 \%$. Weight evolution during the drying process in the temperature range $45^{\circ}-55^{\circ}-60$ ${ }^{\circ} \mathrm{C}$, under the influence of speed drying agent is shown in Fig. 4. 


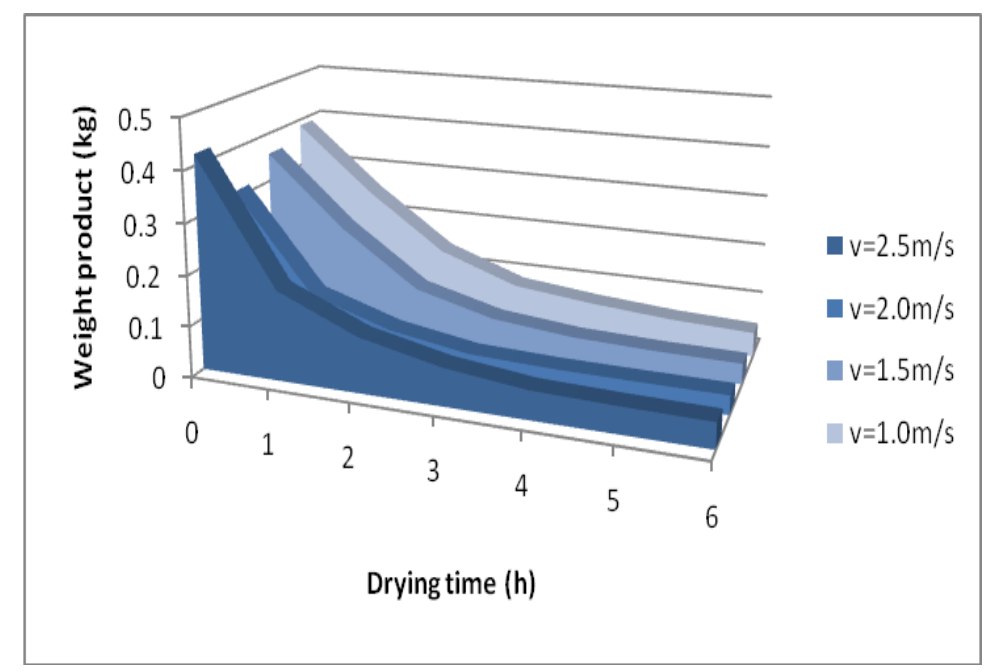

Fig. 4. Evolution of the weight of the products during the drying process

Each experiment was repeated 4 times, in the graph is shown the average. Temperature distribution during the drying of carrots is shown graphically in Fig. 5 (a,b), 6 (a,b).
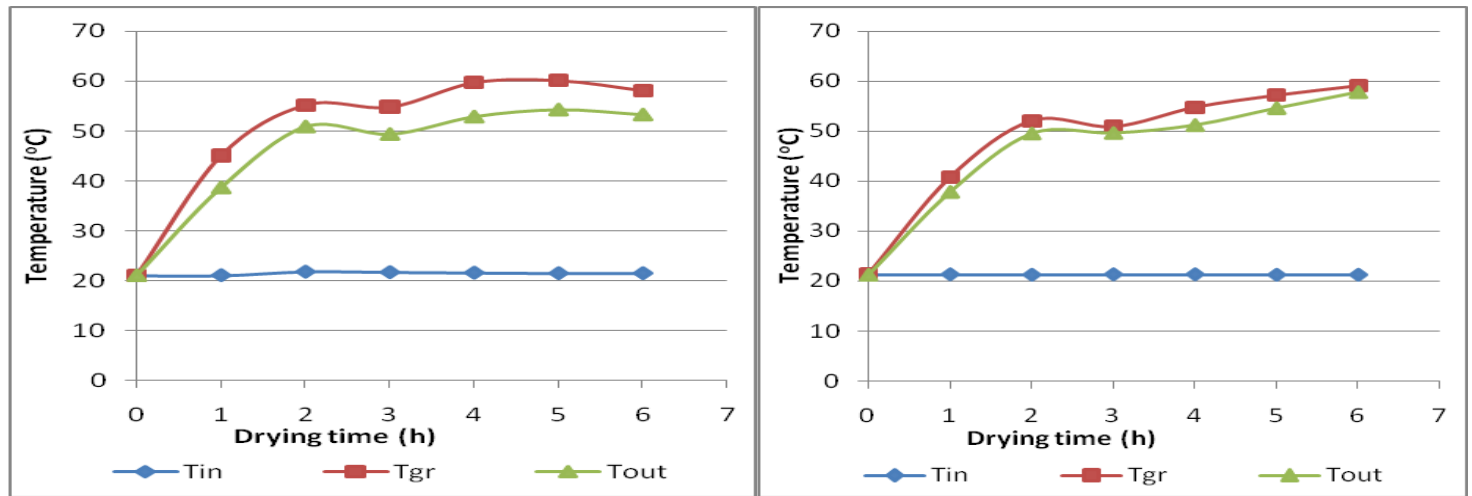

Fig. 5. Temperature profile for M1 and M2
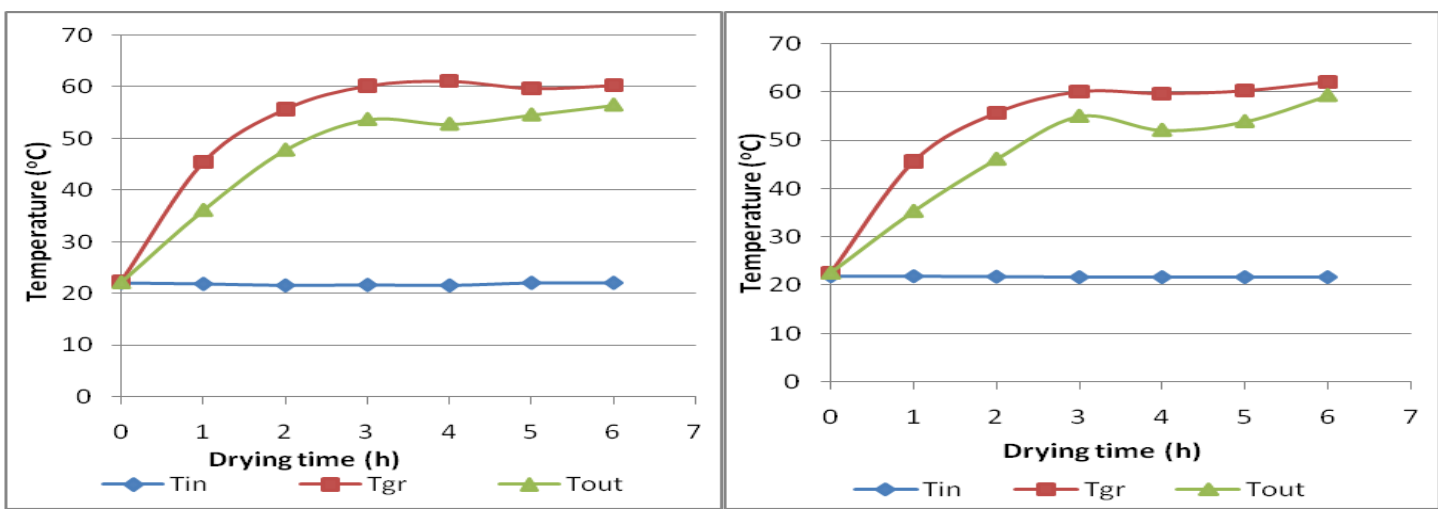

Fig. 6. Temperature profile for M3 and M4

As can be seen from the entry temperature of the drying agent in drier $\left(T_{\text {in }}\right)$ can be maintained constant during the drying process due to the uncontrolled laboratory. 
The initial moisture content of carrot slices divided form, with a thickness of $4 \mathrm{~mm}$ was between 90.66 and $92.15 \%$ (wb), which corresponds to $9.70-11.73 \mathrm{~g}$ water/g $\mathrm{dm}$. The evolution of moisture during the drying process is shown in Fig. 5-7 (a, b).

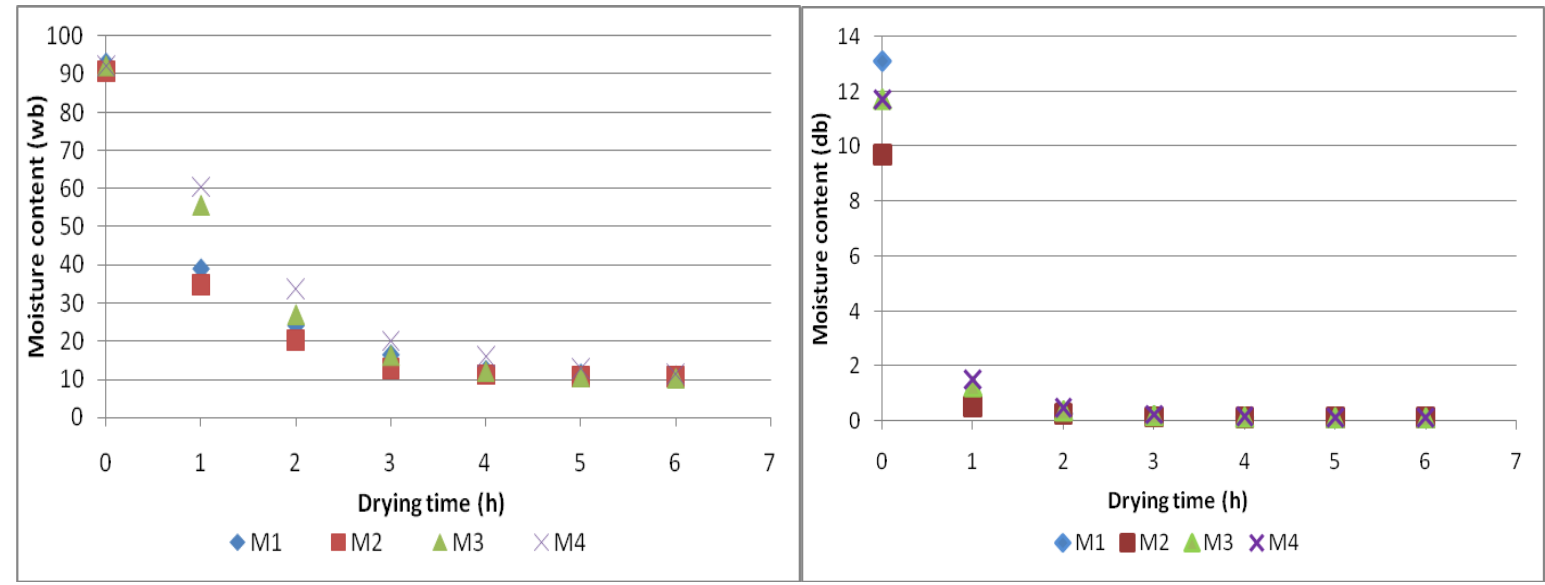

Fig. 7. Variation of carrot cubes moisture ratio with time at different rates of air

The duration of the drying process was 360 minutes. Most of the moisture contained in carrot has been removed in the first 3 hours of the drying process in the types of work.

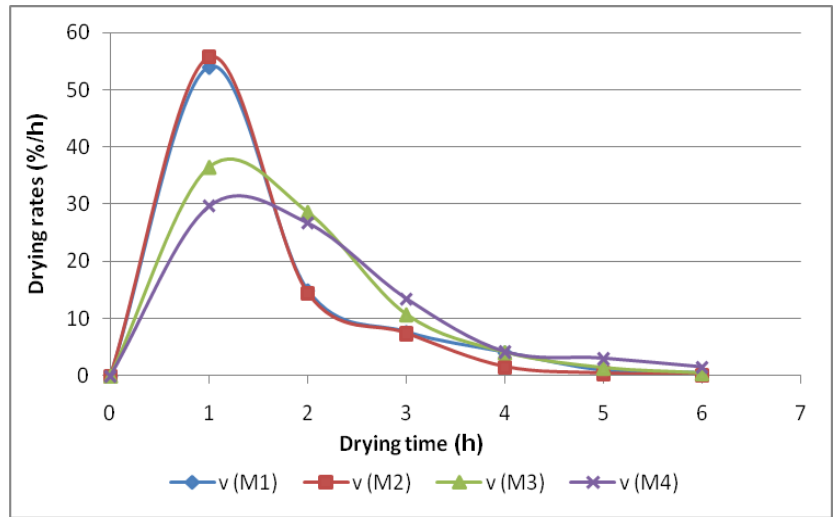

Fig. 8. Drying rate versus time

Increasing the speed of the drying agent results in reduction of the moisture content of the product to the amount of $11.51 \%$ (for $M 4$ ), $10.43 \%$ (for $M 3$ ), $10.78 \%$ (for $M 2$ ) or $10.87 \%$ (M1), as can be seen Fig. 8.

In order to determine the moisture content as a function of drying time, empirical Henderson and Pabis and Page equations were fitted and correlation coefficients $\left(\mathrm{R}^{2}\right)$ were calculated.

The coefficients of correlation and estimated parameters for the two models are presented in Tab. 2. The values of $\mathrm{R}^{2}$ obtained from Page equation are higher than those attained by Henderson and Pabis equation. The $\mathrm{R}^{2}$ values of Page equation vary between 0.996 and 0.998 and between 0.990 and 0.993 for the Henderson and Pabis equation. 
Tab. 2

Statistical results obtained from different thin layer model

\begin{tabular}{|l|c|c|c|c|c|}
\hline \multirow{2}{*}{ Model } & $\begin{array}{c}\text { Air velocity } \\
(\mathbf{m} / \mathbf{s})\end{array}$ & \multicolumn{2}{|c|}{ Constants } & $\mathbf{R}^{\mathbf{2}}$ & SE \\
\hline Page & $M 1$ & $\mathrm{k}=0.0042$ & $\mathrm{n}=1.121$ & 0.996 & 6.97 \\
\cline { 2 - 6 } & $M 2$ & $\mathrm{k}=0.0047$ & $\mathrm{n}=1.151$ & 0.998 & 3.32 \\
\cline { 2 - 6 } & $M 3$ & $\mathrm{k}=0.0099$ & $\mathrm{n}=1.052$ & 0.998 & 3.60 \\
\cline { 2 - 6 } & $M 4$ & $\mathrm{~K}=0.0057$ & $\mathrm{~N}=1.150$ & 0.997 & 3,37 \\
\hline \multirow{4}{*}{$\begin{array}{l}\text { Henderson } \\
\text { ansd Pabis }\end{array}$} & $M 1$ & $\mathrm{k}=0.0088$ & $\mathrm{a}=1.194$ & 0.991 & 8.78 \\
\cline { 2 - 6 } & $M 2$ & $\mathrm{k}=0.0112$ & $\mathrm{a}=1.158$ & 0.993 & 9.67 \\
\cline { 2 - 6 } & $M 3$ & $\mathrm{k}=0.0131$ & $\mathrm{a}=1.005$ & 0.990 & 5.44 \\
\cline { 2 - 6 } & $M 4$ & $\mathrm{~K}=0.0125$ & $\mathrm{a}=1.008$ & 0.991 & 6.31 \\
\hline
\end{tabular}

After 60 days of storage, samples of dried carrots were subjected to the rehydration process. Carrots were maintained at $4{ }^{\circ} \mathrm{C}$ packed in sealed jars. The rehydration capacity of the carrots was determined by holding samples carrots in water at room temperature. The weight of the samples was measured at 30,60 and 120 minutes. After removal from the water, allowed left to dry on absorbent paper to remove excess surface water, and weighed. Samples of the carrots were measured using a sensitive electronic balances of $0.001 \mathrm{~g}$.

Water temperature of rehydration was reaching $28{ }^{\circ} \mathrm{C}$. Rehydration curves indicate a high rate of water absorption, followed by a slower absorption towards the end of rehydration (Fig. 9).

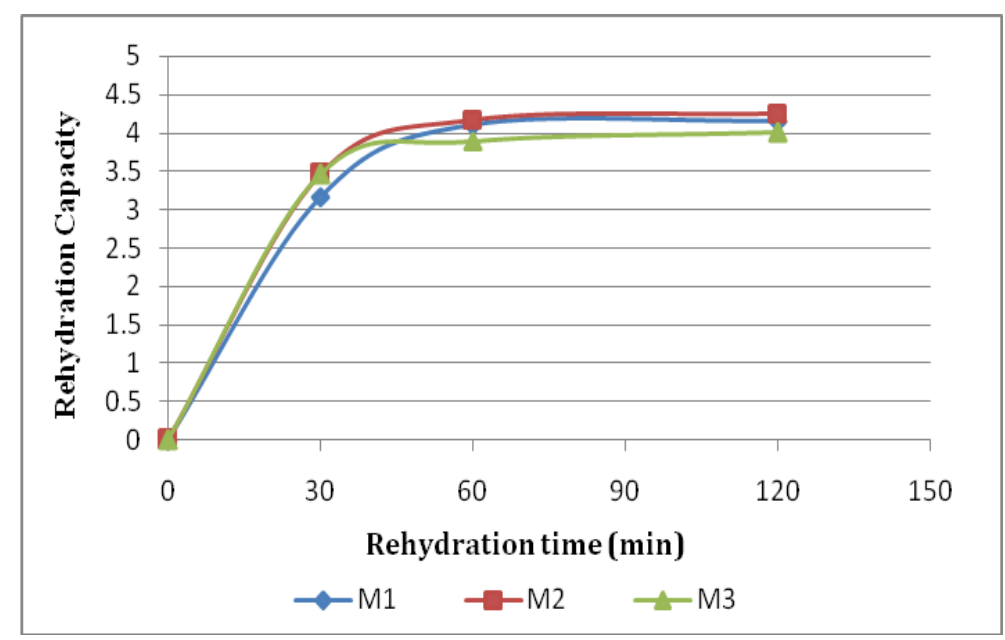

Fig. 9 Rehydration capacity of carrots

High absorption capacity can be explained by the rapid rehydration of capillaries and areas of the surface of the carrots. In terms of capacity rehydration agent speed $2.0 \mathrm{~m} /$ presented the highest values $(3.46,4.18,4.26$ for the period of 30,60 or 120 minutes) when dehydrated carrots at $45-55-60^{\circ} \mathrm{C}$. Some research in the field have concluded that the optimum temperature for rehydration water should be as high as the optimum temperature of $65^{\circ} \mathrm{C}$ for rehydrating tomato (Doymaz I., 2007). 


\section{CONCLUSION}

The most important characteristics of carrot required for simulation and optimization of the drying were studied. The results indicate that, although in the first 60 minutes of the drying process the moisture content of the product is the same for each value of the drying agent.

The relationship between temperature and drying time is not linear exponential characteristic curves showing drying.

Other research in the field have concluded that osmotic pre-treatment had favorable effect compared to traditional methods, both in terms of energy, but also in terms of organoleptic and nutritional product. (Vázquez-Vila, 2009).

It is seen from Fig. 6 that constant speed drying time is very short ( 3 hours), followed by drying period with decreasing speed. The diffusion coefficient increases as the speed of the drying agent. The correlation coefficient $\left(\mathrm{R}^{2}\right)$ and the root-mean-square error ( 22$)$ are used to determine the best solution to dry carrots.

The Page model adequately predicted the moisture content of carrot during the drying process at temperatures $45^{\circ}-55^{\circ}-60^{\circ} \mathrm{C}$, air velocities $1.0 \mathrm{~m} / \mathrm{s}$ to $2.5 \mathrm{~m} / \mathrm{s}$. In terms of capacity rehydration agent speed $2.0 \mathrm{~m} /$ presented the highest values $(3.46,4.18,4.26$ for the period of 30,60 or 120 minutes) when dehydrated carrots at $45-55-60^{\circ} \mathrm{C}$.

Acknowledgements. We would like to thank the POSDRU 77222, Doctoral School of UASVM and Department of Agricultural Mechanization for providing the laboratory facilities and technical support.

\section{REFERENCES}

1. Brennan J. G. (2006). Food processing handbook, Wiley VCH.

2. Catană Luminița, Murad Erol, Catană Monica, Negoiță Mioara, Sima Cristian, Enuța

Iorga, Belc Nastasia, Chițu Viorica (2008). Indrumar pentru realizarea unei unități de deshidratare a legumelor și fructelor", Editura Printech, București.

3. Doymaz I. (2002). Convective air drying characteristics of thin layer carrots, Journal of Food Engineering, 61: 359-364.

4. Mujumdar A. S. (2006). Handbook of Industrial Drying, Taylor and Francis Group.

5. Țenu I., Roșca R., Cârlescu P. (2012). Researches regarding the designing, achievement and testing of a laboratory test rig for drying agricultural and food products. Simpozionul Științific Internațional, Horticultură - Ştiință, Calitate, Diversitate și Armonie, Universitatea de Științe Agricole şi Medicină Veterinară "Ion Ionescu de la Brad" Iași.

6. Vázquez-Vila M. J. (2009). Dehydration kinetics of carrots (Daucus carota L.) in osmotic and air convective drying processes, Instituto Nacional de Investigación y Tecnología Agraria y Alimentaria (INIA) Spanish Journal of Agricultural Research. 4: 869-875. 